\title{
Despojo, baldíos y conflicto armado en Puerto Gaitán y Mapiripán (Meta, Colombia) entre 1980 y 2010
}

\author{
Dispossession, wastelands and armed conflict in Puerto Gaitán \\ and Mapiripán (Meta, Colombia) between 1980 and 2010 \\ Despojo, baldios e conflito armado em Puerto Gaitán e Mapiripán \\ (Meta, Colômbia) entre 1980 e 2010
}

\section{IVONNE RODRÍGUEZ GONZÁLEZ* \\ Verdad Abierta, Colombia}

FECHA DE RECEPCIÓN: 1 DE AGOSTO dE 2013 • FECHA DE ACEPTACIÓN: 28 DE SEPTIEMBRE DE 2013

Doi: dx.doi.org/10.12804/esj16.1.2014.08

Para citar este artículo: Rodríguez González, I. (2014). Despojo, baldíos y conflicto armado en Puerto Gaitán y Mapiripán (Meta, Colombia) entre 1980 y 2010. Estudios Socio-Jurídicos, 16(1), pp. 315-342. doi: dx.doi.org/10.12804/esj 16.1.2014.08

\section{RESUMEN}

Este artículo busca mostrar cómo ocurrió el despojo y la concentración de tierras baldías, y el desarrollo del conflicto en Puerto Gaitán y Mapiripán entre 1980 y 2010. A partir del análisis de registros públicos, mapas y entrevistas realizadas en terreno, este trabajo concluyó que los mecanismos desarrollados por el gobierno para desarrollar una reforma agraria no garantizaron seguridad en los derechos de propiedad, desatando constantes ciclos de despojo.

Palabras clave: Reforma agraria, baldíos, despojo, concentración, paramilitares.

\begin{abstract}
This paper shows how dispossession processes, wastelands concentration and armed conflict happened in Puerto Gaitán and Mapiripán (Colombia) between 1980 and 2010. From the analysis of public records, maps and field interviews, this research concluded that developed mechanisms by the Colombian government for an agrarian reform did not guarantee safety in property rights for local people and that failure unleashed constant cycles of dispossession.
\end{abstract}

Key Words: Land reform, wastelands, dispossession, concentration, paramilitaries.

* Comunicadora social y periodista de la Universidad Autónoma de Bucaramaga, estudiante de la Maestría en Estudios Políticos del IEPRI, Universidad Nacional de Colombia. Periodista VerdadAbierta.com. Correo electrónico: imarcela2728@gmail.com 


\section{RESUMO}

A propriedade rural na Colômbia tem sido adjudicada e concentrada por meio de coligações entre atores legais e ilegais, a coerção e a cooptação de funcionários e mecanismos do Estado. Isto se traduziu em: tentativas frustradas de reforma agrária, ou seja, a distribuição das terras da nação a favor dos camponeses pobres; ciclos de despojo e a acumulação da propriedade por parte de agroindústrias que agora exploram os antigos prédios baldios.

Palavras- chave: A reforma agrária, inculto, entulho, concentração, paramilitar. 


\section{Introducción}

Los intentos de reforma agraria en Colombia no garantizaron derechos de propiedad rural estables. Los mecanismos legales para lograr una distribución de la tierra fueron cooptados por una coalición de actores legales e ilegales, con conexiones desde la región hacia el poder central, sumado a un ejercicio persistente de la coerción que impidió que los beneficiarios de la reforma pudieran permanecer en las parcelas que el instituto de tierras les tituló.

Esta inestabilidad en los derechos de propiedad condujo a varios ciclos de despojo, perpetrados también por vías ilegales y legales, pero que en la cadena final fueron legalizados por los mismos mecanismos que ofrece el Estado. Ello significó no solo una transformación jurídica de la propiedad, sino material, que comenzó con parcelas cultivadas con pancoger y terminó en grandes extensiones de tierra donde se desarrollan proyectos agroindustriales a gran escala.

Esto puede inferirse de estudios de caso realizados en los municipios de Puerto Gaitán y Mapiripán, Meta, donde a finales de la década de 1980 y principios de los años 90 el Instituto de Tierras adjudicó predios baldíos a campesinos que con el tiempo fueron comercializados y acumulados transformándolos en vastos terrenos en los que ahora opera la industria.

Lo anterior sugiere que en Colombia el proceso de restitución de tierras, que nació de la Ley 1448, o Ley de Víctimas, aprobada en junio de 2011 y puesta en marcha desde el 1 de enero de 2012, con dificultad puede plantear una línea divisora entre legalidad e ilegalidad a la hora de documentar las demandas que presenta ante los jueces especializados. Un proceso de restitución integral supone la aceptación de dichas coaliciones de legales e ilegales en el afán de acumular tierras que eran destinadas a la reforma agraria.

En ese sentido, este texto sugiere además que es complejo definir el concepto de buena fe que contempla la Ley de Víctimas. Este es un concepto que los jueces de tierras se supone deben aplicar en procesos de reclamación de tierras, cuando una víctima asegura que fue despojada del predio pero el actual propietario sostiene que lo compró desconociendo el pasado violento de la tierra y sin violar la ley. Con las coaliciones entre 
legales e ilegales, coerción y cooptación de mecanismos del Estado, este concepto atraviesa entonces por una definición y aplicación complejas.

Los casos presentados a continuación evidencian además que el Estado fue débil en garantizar los derechos de propiedad rural y que la doctrina del liberalismo económico en realidad no se tradujo en el ejercicio de un Estado de derecho, en el que todas las personas - sin distinción económicatuvieran en este caso acceso a la tierra rural.

\section{El despojo y la acumulación}

En Colombia varios autores han documentado el despojo de tierras cometido por diferentes actores armados y la transformación de la propiedad rural y su explotación final en manos de agroindustrias. Alejandro Reyes (2009, pp. 15-371) narra los intentos de reforma agraria impulsados durante los gobiernos del último siglo, la influencia del paramilitarismo y el narcotráfico en el despojo, y las modalidades generales de la usurpación de tierras por regiones, con énfasis en las que están sobre zonas de frontera.

Reyes documenta con especial atención el despojo en la costa Caribe, por ejemplo, Sucre, donde la clase terrateniente incentivó el latifundio y la ampliación de las ganaderías, secando los playones y ciénagas, y evitando que los campesinos tuvieran una parcela. El autor también hace un recuento sobre los motivos identificados en el despojo histórico: evitar la distribución de la propiedad rural, controlar el territorio como lugar de guerra, desarrollar cultivos ilegales, 'lavar' las fortunas del narcotráfico e impulsar proyectos a gran escala para aumentar la riqueza.

El trabajo del Grupo de Memoria Histórica en la Tierra en Disputa (2010, pp. 1-527) coincide con el de Reyes en documentar el despojo en la costa Caribe, principalmente en los departamentos de Córdoba, Sucre y la región de los Montes de Montes de María, en los que describe cómo fue la evolución de la estructura agraria, el sistema político regional, las masacres, el despojo directo realizado por actores armados, la compra masiva de tierras y cómo los victimarios, desmovilizados de las AUC beneficiados por la Ley de Justicia y Paz, guardaron silencio frente a estas usurpaciones de tierras. 
Yamile Salinas (2010, pp. 1-57) se enfoca en explicar cómo la tierra rural durante la última década ha sido concentrada por empresas nacionales y extranjeras, y describe los cambios normativos impulsados desde el gobierno que favorecieron el desarrollo de agroindustrias a partir de cultivos extensivos como la palma africana, la caña de azúcar y los forestales. Salinas sostiene que ha habido una concentración de la propiedad rural sobre todo en la región de la altillanura orinoquense, en el corredor que conecta al Meta con el Vichada, favorecida por incentivos estatales pero también a punta de la violación de normas rurales, como la Ley 160 de 1994 que prohíbe la acumulación de predios de origen baldío.

Aunque la producción académica referenciada ha sido clave de forma inicial para comprender los mecanismos de despojo que operaron en la usurpación de tierras rurales en el país, los actores que intervinieron y, de forma más reciente, la acumulación de predios baldíos por parte de agroindustrias, aún persisten algunos vacíos como la explicación de estos mecanismos en una región como la altillanura, el detalle de cómo en el tiempo la propiedad sufrió una transformación jurídica y material, y cómo el despojo fue legalizado por la vía del derecho.

Los estudios de Reyes y del Grupo de Memoria Histórica enfatizan en la historia del despojo en la región Caribe y Salinas, en la concentración de tierras por empresas nacionales y extranjeras en la altillanura. Sin embargo, ninguno explica la conexión entre las tierras usurpadas a través de mecanismos legales e ilegales, la transformación de la propiedad rural traducida en acumulación y la participación minuciosa de hacendados, funcionarios públicos, grupos paramilitares y empresarios en la comercialización de las tierras. A partir de un estudio de caso, esta investigación pretende dilucidar el tema y dejar la puerta abierta sobre la caracterización de otras regiones.

Esta investigación retoma la propuesta de Daniel Fitzpatrick (2006) sobre los derechos de propiedad. El autor explica que alrededor de estos confluyen varios elementos: las alianzas entre los actores sociales, las reglas informales que se imponen en el ámbito local y que superan las del orden nacional, el pluralismo en las normas que rigen la propiedad y la coerción ejercida por el Estado.

Estos elementos explican la realidad del campo en Colombia, donde, pese a los esfuerzos por lograr una formalización de los predios, con algunos intentos por adjudicar tierras baldías y actualizaciones del catastro, no se 
ha reducido el conflicto. "En algunos casos, estos errores en los programas han sido resultado de la distribución de las tierras desde la misma titulación. A largo plazo, el conflicto se debió a que los ocupantes de las tierras, personas pobres o vulnerables, fueron despojados por los grupos más ricos y poderosos". (Fitzpatrick, 2006, p. 1.013).

Fitzpatrick argumenta que hay una constante tensión entre las leyes que impone el Estado y las leyes informales que establecen los actores locales como ganaderos, agricultores, comerciantes, gremios y colonos. Para el caso de países del tercer mundo, como Colombia, la coerción y los intereses de los actores locales con más poder han prevalecido.

Cuando un Estado es capturado por la minoría de grupos de interés, puede preferir la inseguridad y la incertidumbre en los derechos de propiedad para facilitar la búsqueda de rentas [...] las agencias estatales pueden otorgar derechos a los compinches sin necesidad de incurrir en la obligación de compensar a desposeídos ocupantes, ya que estos ocupantes o bien carecen de derechos formales de propiedad o su acceso a las instituciones judiciales es insuficiente. (Fitzpatrick, 2006, p. 1041).

\section{Los casos}

Este estudio seleccionó varios casos del departamento del Meta para analizar la relación entre el despojo de tierras, la apropiación de baldíos y el conflicto armado colombiano desde 1980 hasta 2010, teniendo en cuenta varios criterios. Primero, fue una región donde confluyeron diferentes actores armados durante los últimos cincuenta años: las FARC, que instaló su principal centro de operaciones con diferentes frentes del Bloque Oriental, las autodefensas, venidas de Puerto Boyacá, narcotraficantes, paramilitares del Bloque Centauros de las Auc y Autodefensas Campesinas del Casanare y, de forma más reciente, las llamadas bandas criminales.

Segundo, porque es la zona del país con la mayor cantidad de tierra reclamada en restitución con 668.000 hectáreas, ${ }^{1}$ en aplicación a la Ley 
1448 o Ley de Víctimas y Restitución de Tierras. Los tres casos estudiados están además en Puerto Gaitán y Mapiripán, precisamente los dos municipios con más reclamantes y área solicitada en restitución del departamento: el primero con 309 solicitudes por 146.842 hectáreas y el segundo, con 475 solicitudes por 206.657 hectáreas. Y tercero, porque fue una región definida por el Plan Nacional de Desarrollo (Departamento Nacional de Planeación, 2010, pp. 1-541) del gobierno de Juan Manuel Santos (20102014) como el lugar para desarrollar la 'locomotora agrícola', es decir, impulsar la agroindustria y expandir la llamada frontera agrícola en la altillanura.

La reconstrucción de los siguientes casos es producto de un trabajo de campo realizado por periodistas del portal VerdadAbierta.com (2013), ${ }^{2}$ cuyos hallazgos empíricos fueron publicados en abril de 2013 y que en este artículo han sido teorizados. El trabajo metodológico partió de la selección de tres empresas demandadas ante la justicia ordinaria por el Instituto Colombiano de Desarrollo Rural, Incoder, por violar la Ley 160 de 1994, que prohíbe la acumulación de unidades agrícolas familiares (UAF) cuando las tierras provienen de baldíos, tierras que se supone deben ser tituladas a campesinos.

Los casos están soportados en entrevistas realizadas a las personas que reclaman las tierras y a empresarios, ${ }^{3}$ así como en un archivo compuesto por los folios de matrícula de las tierras que explotan estas empresas. La información contenida en tales documentos públicos fue sistematizada en una base datos para reconstruir el pasado de la propiedad, es decir, a quién pertenecía y cómo con el tiempo fue transferida a empresarios, así como para hallar información adicional sobre los compradores y vendedores en la red, y en archivos oficiales y extraoficiales.

2 La autora del presente artículo académico participó en todas las etapas de la investigación periodística que se publicó en el portal VerdadAbierta, desde la búsqueda de las fuentes, la recolección y análisis de documentos, las entrevistas, el reportaje en campo (municipios de Puerto Gaitán y Mapiripán), el desarrollo de mapas, la escritura de los textos y la planeación de los productos multimedia. El trabajo fue realizado junto al periodista Óscar Parra. La edición de los textos y la asesoría editorial fue realizada por María Teresa Ronderos, directora del proyecto periodístico.

3 Entrevistas realizadas a campesinos de Puerto Gaitán y Mapiripán; las identidades se reservan por razones de seguridad; y entrevista al empresario de Poligrow, Carlo Vigna Taglianti, realizadas entre enero y abril de 2013 como parte del trabajo de campo realizado por periodistas de VerdadAbierta.com. 


\section{Caso 1: El Brasil, las tierras de La Fazenda, Puerto Gaitán, Meta}

El Brasil es un predio de 16.000 hectáreas en la vereda La Cristalina, en Puerto Gaitán, Meta, y explotado en la actualidad por La Fazenda, una empresa que produce y comercializa carne de cerdo. ${ }^{4}$ Treinta años atrás estas tierras pertenecían a la nación, por lo que el antiguo Instituto Colombiano de la Reforma Agraria, Incora, tituló 16 parcelas, ${ }^{5}$ cada una de 1.000 hectáreas, a igual número de familias campesinas que habían llegado a esta zona de los Llanos Orientales desplazadas de la violencia bipartidista de los años 50.

Estas titulaciones comenzaron a finales de la década de 1980, cuando en la región comenzaban a hacer presencia los llamados grupos de autodefensa, financiados por terratenientes para defender la propiedad de los secuestros y extorsiones de la guerrilla, así como por narcotraficantes para proteger sus tierras y rutas de droga. Puerto Gaitán es vecino del departamento de Vichada y para la época en ese lugar había surgido un grupo de autodefensas financiado por narcotraficantes de Puerto Boyacá, a cargo de José Baldomero Linares alias 'Guillermo Torres' ('Los Carranceros' que se tomaron el Oriente del Meta, 20126).

Entre finales de los 80 y comienzos de la siguiente década ese grupo ilegal aumentó en integrantes que ya no solo delinquían en Vichada sino que rondaban por las tierras del departamento vecino, Meta. En la región comenzaron a llamarlos 'Los Carranceros' porque eran apoyados por el esmeraldero Víctor Carranza (Carranza y el Llano, 20117), que había comprado extensas tierras en la región y financiaba este grupo ilegal para proteger sus terrenos y negocios.

En 1995 el Incora había terminado de titular las 16 parcelas a las familias en la vereda La Cristalina. Aunque cada parcela fue bautizada con

4 Certificado de existencia y representación legal de la Sociedad Agropecuaria S.A., de la cual hace parte La Fazenda, Cámara de Comercio de Bucaramanga, 29 de marzo de 2012.

5 Resoluciones 81, 82, 83, 84, 129, 156, 204, 264, 265, 266 y 269 del 27 de marzo de 1995 y 1146 y 1147 del 19 de diciembre de 1995, del antiguo Instituto Colombiano para la Reforma Agraria, Incora.

6 Publicado partir de una versión libre conjunta ante la Unidad de Justicia y Paz de desmovilizados de las Autodefensas Campesinas de Meta y Vichada, AACMV.

7 Publicado a partir de una versión libre rendida por el ex jefe paramilitar Salvatore Mancuso el 5 de diciembre de 2011 ante la Unidad de Justicia y Paz desde una cárcel en Estados Unidos. 
un nombre individual, los colonos le decían al terreno El Brasil por su gran extensión. Ese año 'Los Carranceros' llegaron a las tierras de los campesinos, tomaron por la fuerza la vereda e instalaron un centro de operaciones. Las habitaciones de la casa quinta se adecuaron: una como centro de comunicaciones, otra para torturas y una más para la recuperación de sus integrantes. El resto del terreno lo utilizaron como una 'escuela de entrenamiento' donde los paramilitares recibían clases de táctica militar y manejo de armas. ${ }^{8}$

Durante los siguientes años, El Brasil se convirtió en una base paramilitar. En 1997 sirvió de refugio para los 80 paramilitares provenientes del Urabá que en julio de ese año viajaron desde San José de Apartadó (Antioquia) hasta San José del Guaviare (Guaviare) para cometer la masacre de Mapiripán. ' 'Los Carranceros' reclutaron menores que fueron entrenados y que por "desobediencia" fueron asesinados y arrojados en fosas cavadas en la gran finca. Fue el caso, por ejemplo, de alias 'La Gomelina' que fue asesinada el día que amenazó al grupo con denunciarlos. ${ }^{10}$

'Los Carranceros' se hicieron llamar Autodefensas Campesinas de Meta y Vichada, ACMV, para desmovilizarse en 2005. ${ }^{11}$ Durante diez años, entre 1995 y 2005, la finca fue ocupada por el grupo paramilitar pero, tras la desmovilización, el predio comenzó a sufrir una transformación jurídica y material. Aunque no sabe si fue bajo presión o compras a precios irrisorios, los campesinos que habían sido titulados entre los 80 y principios de los 90 cedieron las parcelas de El Brasil a una empresa de la familia de Víctor Carranza.

En marzo de 2001 y febrero de 2007 (corrección del autor por precisión en fechas), tres parceleros vendieron sus tierras a familiares y amigos

8 Entrevista a fiscales de la Unidad de Justicia y Paz realizada en diciembre de 2012, cuyas identidades se reservan por razones de seguridad. La entrevista fue realizada por los periodistas Óscar Parra e Ivonne Rodríguez en las oficinas del búnker de la Fiscalía General de la Nación en Bogotá.

9 Condena de la Comisión Interamericana de Derechos Humanos (CIDH) contra el Estado Colombiano por la masacre de Mapiripán, Meta, ocurrida en julio de 1997, fallo del 4 de marzo de 2005.

10 Ibíd. Entrevista a Fiscales de la Unidad de Justicia y Paz, quienes aseguraron que en el antiguo predio el Brasil la Unidad de Exhumaciones realizó varias inspecciones y encontró seis cuerpos, de los cuales cuatro fueron identificados y correspondían a menores reclutados por el grupo paramilitar.

11 Acta de desmovilización, Resolución 157 de 2005 que confirmó la entrega de armas de las Autodefensas Campesinas de Meta y Vichada (ACMV), ocurrida el 6 de agosto de 2005 en la finca La María, vereda San Miguel, en el municipio de Puerto Gaitán Meta, firmada por el Alto Comisionado para la Paz, Presidencia de la República. 
de los Carranza. ${ }^{12}$ En marzo de 2007 (corrección del autor por precisión en fecha), los otros trece propietarios le firmaron un poder al abogado Fernandel Alfonso, quien se encargó de presentar todos los documentos a la notaria 4 de Villavicencio, Gloria Emma Camacho Romero. ${ }^{13}$ En esa notaría fue creada la empresa Agualinda, ${ }^{14}$ cuya representante legal es María Blanca Carranza, ${ }^{15}$ esposa del empresario de las esmeraldas, y fueron transferidos los 16 predios como aporte de capital a esta nueva empresa. ${ }^{16}$ Estas transacciones fueron legalizadas ante el registrador Jairo Alfonso Gutiérrez, de la Oficina de Instrumentos Públicos de Puerto Gaitán. ${ }^{17}$

En esta transferencia, la firma de un campesino fue falsificada. El propietario estaba muerto para el momento en que las parcelas fueron englobadas y entregadas a la empresa Agualinda. Siete días después de la constitución de Agualinda y de la transferencia de los predios a esta empresa, la familia Carranza los negoció con un grupo de empresarios santandereanos y antioqueños llamado Aliar. El 10 de abril de 2007 Agualinda firmó ${ }^{18}$ con ellos una promesa de compraventa por las 16.000 hectáreas pero, para poder hacer esta transferencia, el 2 de mayo de 2007, ante la misma Notaría 4 y la Oficina de Instrumentos Públicos, la empresa de Carranza englobó primero los 16 predios. ${ }^{19}$ El 15 de mayo Agualinda y Aliar oficializaron la transferencia de las tierras mediante la celebración de un contrato de fiducia, venta y comodato por 15.000 millones de pesos. Tal contrato que firmó

12 Compraventas firmadas por los adjudicatarios del Incora a Yesid Carranza Córdoba, Yesid Eduardo Chaparro Alfonso y Miguel Alfonso Velosa el 28 de marzo de 2001 para el primer caso, y el 27 de febrero de 2007 para el segundo y tercer casos.

13 Trece poderes firmados por los adjudicatarios originales presuntamente (porque uno de ellos estaba muerto para la época según certificado de defunción emitido por la Registraduría Nacional del Estado Civil) y entregados al abogado Julio César Pérez Niño para constituir una sociedad comercial tipo anónima. Todos dicen ser copropietarios de los predios. Los documentos son firmados el 26 de marzo de 2007.

14 Escritura 0649 de la Notaría Cuarta de Villavicencio, firmada el 3 de abril de 2007.

15 Certificado nacional Cámara de Comercio de Villavicencio, que da fe del nombramiento de Sergio Andreiv Poveda como gerente y de María Blanca Carranza como suplente del gerente, de la empresa Agualinda.

16 Escritura 0950 de la Notaría Cuarta de Villavicencio, firmada el 10 de mayo de 2007.

17 Folio de matrícula 234-0015549, que contiene la tradición del predio El Brasil, registrada el 9 de mayo de 2007 en Círculo Registral de Puerto López.

18 Escritura 2676 de la Notaría 3 de Bucaramanga, en la que se celebra el contrato de fiducia, venta y comodato, 15 de mayo de 2007.

19 Ibíd. Folio de matrícula 234-0015549, que contiene la tradición del predio El Brasil, registrada el 9 de mayo de 2007 en Círculo Registral de Puerto López. 
Aliar fue una estrategia financiera para poder explotar las tierras acumuladas sin que estas quedaran a su nombre directamente.

Aliar fue constituida con diez empresas ${ }^{20}$ (seis santandereanas y cuatro de Medellín, estas últimas creadas un mismo día en Envigado) para poder acumular las 16.000 hectáreas de El Brasil, que originariamente eran baldíos titulados a campesinos. Los representantes de cada una de estas empresas han sido miembros en su mayoría de la junta de Aliar. ${ }^{21}$ Una de esas empresas socias es La Fazenda, que desde 2007 comenzó a adecuar las tierras para cultivarlas con soya y maíz. Con estos cereales, el proyecto alimenta los cerdos que crecen en otra finca de 16.000 hectáreas, también de propiedad de Aliar, en Puerto Gaitán, pero que no colinda con El Brasil.

La Fazenda sigue explotando las tierras sin que haya habido una actuación de las autoridades. En el Congreso varios parlamentarios del Polo Democrático $^{22}$ denunciaron que esta agroindustria debe ser investigada porque acaparó tierras de origen baldío.

\section{Caso 2: Hato Cabiona, las tierras explotadas por La Cristalina, Puerto Gaitán, Meta}

El Hato Cabiona ${ }^{23}$ es un predio de 25.000 hectáreas en el caserío El Porvenir, en Puerto Gaitán, Meta, y explotado en la actualidad por La Cristalina, una empresa ganadera. ${ }^{24}$ La historia de estas tierras se remonta a la década de los años 50 cuando campesinos desplazados por la violencia llegaron a esta zona de los Llanos Orientales buscando una parcela dónde sobrevivir.

20 Escrituras 3.324, 3.325, 3.326 y 3.327 de la Notaría Séptima de Medellín, firmada el 22 de diciembre de 2006, con las que se constituyen las sociedades anónimas Agropecuarias San Martino, Visión, Valores y Futuro, en Envigado, Antioquia, y certificados de Cámara de Comercio de las empresas santandereanas Entrehogar (1992), Premex (1979), Prollanura (2007), La Fazenda (2004), Inversiones Arar (1996) y Concesionaria (1987).

21 Ibíd. Certificado de existencia y representación legal de la Sociedad Agropecuaria S.A., de la cual hace parte La Fazenda, Cámara de Comercio de Bucaramanga, 29 de marzo de 2012.

22 Debate de control político sobre tierras, representante Iván Cepeda, plenaria de Senado, mayo de 2012.

23 Veintisiete resoluciones de adjudicación del antiguo Instituto Colombiano de Reforma Agraria, Incora, de las cuales 25 fueron adjudicadas el 15 y 16 de enero de 1992, y dos más en septiembre de 1996.

${ }^{24}$ Cartas enviadas por la empresa ganadera a los colonos que reclaman las tierras, firmada el 26 de junio de 2009 por el administrador Jhon Jairo Ramírez. 
Entre los primeros colonos estuvo Víctor Machado, quien con el tiempo se convirtió en un hombre próspero. Llegó a la región con una empresa petrolera que realizaba explotación, construyó una casa y asumió como suyas 25.000 hectáreas a las que llamó Hato Cabiona. Machado permitía que nuevos colonos se instalaran en el hato, cultivaran y sus ganados pastaran sin problema. ${ }^{25}$

Entre Machado y los colonos no hubo conflictos hasta que el hacendado murió y a la región llegaron unos hombres que se hacían llamar 'Masetos', un grupo derivado de una alianza de narcotraficantes conocida como Muerte a Secuestradores (MAS) que en el Meta asesinó a varios líderes de izquierda e integrantes de la Unión Patriótica, UP. En 1986 este grupo se tomó el hato e instaló en una parte del gran terreno su centro de operaciones (Cinep, 2004).

La situación se complicó aún más cuando Machado murió ese año y la viuda le vendió las mejoras al esmeraldero Víctor Carranza. En 1987 'Los Masetos' asesinaron a varios líderes y campesinos de El Porvenir y provocaron los primeros desplazamientos. En 1989, un frente de las FARC venido del Vichada expulsó al grupo paramilitar del Hato Cabiona.

Sin embargo, la violencia siguió. Antiguos 'Masetos' y paramilitares de Puerto Boyacá (Carranza y el origen de las Autodefensas en Puerto Boyacá, $2011^{26}$ ) se sumaron al grupo de autodefensas de José Baldomero Linares alias 'Guillermo Torres', financiado por Víctor Carranza. 'Los Carranceros' comenzaron a rondar estas tierras de Puerto Gaitán mientras que los antiguos colonos, pese a la violencia, trataban de seguir viviendo en el hato.

Lo que no sabían los colonos originarios es que mientras ellos explotaban las tierras, el antiguo Instituto Colombiano para la Reforma Agraria, Incora, le titulaba estas tierras a 27 personas que ni siquiera conocían la región y en su vida las habían pisado. Con su poder, Víctor Carranza logró que el Incora le titulara el Hato Cabiona entre 1994 y 1998 a amigos y trabajadores. Algunos de los titulados fueron Joaquín Silva Ramos, quien fue su escolta, y Carlos Castillo Laverde, socio del empresario en la compra de otro predio llamado Morichito, también en Puerto Gaitán.

25 Entrevista realizada a una familia originaria y reclamante de tierras, cuya identidad se reserva por razones de seguridad. La entrevista fue realizada en Bogotá en abril de 2013 por los periodistas Óscar Parra e Ivonne Rodríguez.

26 Publicada a partir de las versiones libres ante la Unidad de Justicia y Paz de Alonso de Jesús Baquero, alias 'Vladimir' y Gerardo Zuluaga, alias 'Ponzoña'. 
Estas transferencias fueron desconocidas por los colonos originarios porque ninguno de los titulados por el instituto de tierras apareció a reclamarlas. Supieron que sus tierras tenían otro dueño en el papel tras la desmovilización de los 'Los Carranceros' en 2005, cuando trabajadores de la ganadería La Cristalina les dijeron que ellos eran los propietarios de esas tierras y que retiraran el ganado de los pastos so pena de que los animales fueran sacrificados.

En 2007, primero ante la notaría 4 Villavicencio, Gloria Emma Camacho Romero, y luego ante el registrador, Jairo Alfonso Gutiérrez, de la Oficina de Instrumentos Públicos de Puerto Gaitán, los 27 titulados, amigos y trabajadores de Carranza, englobaron las 25.000 hectáreas del hato Cabiona en otros cinco predios: Mi Llanura, El Pedregal, El Rincón, Campohermoso y Las Corocoras. ${ }^{27}$ La transferencia la hicieron con el abogado Fernandel Alfonso y en tres casos falsificaron las firmas de tres de los adjudicados, porque al momento del englobe estaban muertos. ${ }^{28}$

Los nuevos propietarios de los cinco globos también fueron cercanos a Carranza. El predio Mi Llanura fue cedido a Pedro Libardo Ortegón (Capturado Piloto de El Mexicano, 1996), quien fue piloto del narcotraficante Gonzalo Rodríguez Gacha 'El Mexicano', financiador de las Autodefensas de Puerto Boyacá y de grupos de autodefensas en los Llanos Orientales. Otro de los predios, el Rincón, le fue entregado a Hugo Armando Bustos Bernal, miembro suplente de la junta directiva de la Compañía Ganadera del Meta, ${ }^{29}$ de la cual su miembro principal es Ernesto Carranza, ${ }^{30}$ un hijo del esmeraldero.

Los otros predios quedaron a nombre de personas con cédulas de Muzo, Boyacá, la zona de esmeraldas controlada por la familia Carranza, y fueron administrados por Celso Hinojosa, ${ }^{31}$ un empleado de confianza del empresario de las esmeraldas. En 2008 Hinojosa fue el encargado de

27 Escrituras 2918 y 2919 del 20 de diciembre de 2007, registradas en la Notaría 4 de Villavicencio.

28 Actas de defunción que reposan en la Registraduría Nacional del Estado Civil.

29 Certificado de integrantes de juntas Compañía Ganadera del Meta.

30 Declaración jurada de Víctor Carranza, indagatoria, hoja 3, radicación 32995, proceso en justicia ordinaria.

31 Cartas firmadas por Celso Hinojosa y repartidas a los colonos reclamantes del Hato Cabiona, 2010. 
enviar "papeletas" a los antiguos colonos del hato reiterándoles que tenían que retirar el ganado de los pastos porque las 25.000 hectáreas le pertenecían a la ganadería La Cristalina.

El caso fue denunciado en el Congreso, y la Superintendencia de Notariado y Registro ${ }^{32}$ corroboró que, en efecto, el antiguo Incora tituló a personas sin que cumplieran los requisitos de la reforma agraria, en este caso, 27 personas que ni conocían los predios, pero que además había una acumulación indebida de ellas. Por sugerencia de un abogado de confianza de Carranza y defensor de los desmovilizados de 'Los Carranceros' en el proceso de Justicia y Paz, cuatro de los cinco propietarios de los predios en que se había englobado el hato se presentaron a la Superintendencia ${ }^{33}$ y reconocieron la irregularidad, prácticamente entregando la tierra.

Celso Hinojosa ${ }^{34}$ murió presuntamente de un infarto a principios de 2013 y Pedro Libardo Ortegón (Los últimos minutos de 'Don Pedro Esmeralda' en el centro de Bogotá, 2013), el único que no reconoció la irregularidad, fue asesinado el 26 de julio en Bogotá. Los antiguos colonos del hato siguen esperando que el Instituto Colombiano para el Desarrollo Rural, Incoder, anule los títulos que adjudicó en la década de los años 90 a los amigos de Carranza y, en cambio, les adjudique a ellos las 25 mil hectáreas que han explotado durante por lo menos 30 años.

\section{Caso 3: Macondo, las tierras explotadas por Poligrow; Mapiripán, Meta}

Macondo es un predio de 5.500 hectáreas en Mapiripán, ${ }^{35}$ Meta, explotado en la actualidad por Poligrow, ${ }^{36}$ una empresa que dice ser multinacional y que tiene las tierras sembradas con palma africana. La historia

32 Informe ejecutivo de los resultados de investigación adelantada por la SNR en la Oficina de Registro de Instrumentos Públicos de San Martín de los Llanos, departamento del Meta, Proyecto de Tierras, Superintendencia de Notariado y Registro, agosto de 2011.

33 Entrevista con funcionaria de la Superintendencia, realizada por Ivonne Rodríguez en abril de 2013. La identidad de la funcionaria se reserva a petición de ella por el riesgo que implica su trabajo.

34 Testimonios de la región de la altillanura, cuya identidad se reserva; entrevistas de marzo de 2013, realizadas por los periodistas Óscar Parra e Ivonne Rodríguez.

35 Folios de matrícula 236-25478, 236-24605 y 236-25411 registrados en la Oficina de Instrumentos Públicos de San Martín, Meta.

36 Certificado de la Cámara de Comercio, Poligrow Colombia Ltda., sede Chapinero, Bogotá, 16 de enero de 2013. 
de estos predios tiene tradición en la década de los años 50, cuando a los Llanos Orientales llegaron colonos desplazados por la violencia y en el caso del sur del país, extranjeros que vieron la oportunidad de hacerse a grandes extensiones de baldíos.

Los primeros colonizadores de Mapiripán fueron los Kirby (Alcaldía de Mapiripán, 2007), una pareja de estadounidenses que compró las mejoras de una finca a la que ellos bautizaron como La Mapiripana. Durante los siguientes años la familia no tuvo problema en que nuevos colonos, sobre todo campesinos expulsados de otros territorios, se asentaran en terrenos de la hacienda y cultivaran pancoger.

En la década de los años 70 empresarios antioqueños vieron que la adjudicación de tierras en el sur del país era rentable. Uno de ellos fue Argemiro Meza, ${ }^{37}$ quien comenzó a comprarles las fincas a colonos a bajos precios para luego ofrecérselas a sus amigos. Aunque las tierras no eran fértiles, eran aptas para la ganadería. Así, a Mapiripán llegaron varios ganaderos, entre ellos uno cuya influencia logró que en 1988 y 1989 el antiguo Instituto Colombiano de Reforma Agraria le titulara a él y a su mayordomo ${ }^{38}$ una hacienda de 5.500 hectáreas a la que llamó Macondo.

Colonos sin títulos y ganaderos con papeles en regla siguieron explotando las tierras hasta que la violencia comenzó a expulsarlos. La señora Kirby abandonó las tierras después de ser secuestrada y de que su esposo falleciera. Muchos ganaderos se fueron por la amenaza de las FARC.

El detonante de la violencia fue en la década de los años 90. El Frente 44 de las FARC hacía presencia en Mapiripán por ser un sitio estratégico para el cultivo de la coca y la comercialización de la cocaína. A un paso del pueblo, en el Guaviare, el vecino departamento, pasando el río, el jefe paramilitar Vicente Castaño tenía sus laboratorios de droga. Los Castaño, fundadores de las AUC, querían controlar el negocio y, con el pretexto de combatir la subversión, atacaron a Mapiripán en julio de 1997.39

37 Entrevistas realizadas en Mapiripán, Meta, a pobladores fundadores. Sus identidades se reservan por razones de seguridad. Las entrevistas fueron realizadas en abril de 2013 por los periodistas Óscar Parra e Ivonne Rodríguez.

38 Resoluciones 1557 de 1998, 1055 de 1989 y 2125 de 1989 del Instituto Colombiano de Reforma Agraria, Incora.

39 Ibídem. Condena de la Comisión Interamericana de Derechos Humanos (CIDH) contra el Estado Colombiano por la masacre de Mapiripán, Meta, ocurrida en julio de 1997, fallo del 4 de marzo de 2005. 
Ese mes enviaron un grupo de paramilitares desde el Urabá antioqueño que, con el apoyo de las fuerzas militares, cometió una masacre en la que fueron torturadas, asesinadas y descuartizadas decenas de personas, ${ }^{40}$ según los relatos de los mapiripenses. El ganadero dueño de Macondo abandonó el pueblo por la violencia que arreciaba cada vez más. ${ }^{41}$

Entre 1997 y 1998, la violencia desplazó a por lo menos 1.300 personas de Mapiripán. ${ }^{42}$ Durante los años siguientes, guerrilleros y paramilitares siguieron la disputa por el territorio, y los colonos originarios, que no tenían títulos, trataron de resistir en el pueblo. En el Meta, el grupo de las AUC de los hermanos Castaño se hizo llamar Bloque Centauros de las AUC y aumentó en hombres durante 2002 y 2004, cuando Vicente Castaño encargó a los narcotraficantes Miguel Arroyave alias 'El Arcángel' y Daniel Rendón alias 'Don Mario'('Don Mario': sin Justicia y Paz..., 2013) al grupo paramilitar. Mapiripán, para los Castaño, seguía siendo un punto clave para el manejo del negocio del narcotráfico y por ello Los Centauros permanecieron en la zona hasta 2006, cuando ocurrió la desmovilización.

El dueño de Macondo nunca supo qué había sucedido con Macondo. ${ }^{43}$ No le interesaba. Había levantado una empresa en Medellín, Antioquia, y dijo que había decidido olvidarse de esa tierra violenta. Al parecer, las 5.500 hectáreas le fueron robadas porque el ganadero asegura que nunca vendió y que se enteró por los medios que su hacienda era explotada por una empresa de palma.

La transferencia de los predios comenzó en 1999,44 dos años después de la masacre, cuando las tierras fueron abandonadas. Una persona identificada como Ángela María Mejía Santamaría supuestamente compró ese año la hacienda Macondo al ganadero y mayordomo por \$30 millones. En 2002, Mejía Santamaría le vendió uno de los predios que integraba la hacienda a otra persona identificada como Luis Carlos Quinchía Restrepo por $\$ 10$ millones de pesos.

40 Sobre el número de víctimas de esta masacre no hay un consenso entre los reportes que hace la comunidad y la investigación que adelanta la Unidad de Justicia y Paz de la Fiscalía.

41 Entrevista realizada en abril de 2013 al ganadero dueño de los predios Macondo, de quien se reserva la identidad por razones de seguridad. Entrevista realizada por el periodista Óscar Parra.

42 Datos del antiguo Registro Único de Población Desplazada, Rupd.

43 Ibíd. Entrevista realizada en abril de 2013 al ganadero dueño de los predios Macondo.

44 Ibíd. Folios de matrícula. 
En 2006 los paramilitares del Bloque Centauros se desmovilizaron ${ }^{45}$ y la hacienda Macondo continuó abandonada. La violencia y el desplazamiento fue tal que un año después, en 2007, el Comité Municipal de Protección a la Población Desplazada ${ }^{46}$ decidió proteger todas las veredas de Mapiripán para evitar el riesgo de que las tierras fueran comercializadas. Para que una tierra pudiera ser vendida, todos los miembros del Comité debían reunirse y dar la aprobación.

En 2009 Ángela María Santamaría y Roberto Quinchía le vendieron la hacienda Macondo por $\$ 4.000$ millones de pesos a la empresa Poligrow. El ganadero originario, quien logró los títulos del Incora a finales de la década de los 80, asegura que nunca les vendió a los primeros, y Poligrow, para poder comprar estas tierras protegidas, asegura que logró el permiso directo con la entonces alcaldesa de Mapiripán, Maribel Mahecha. Fue la mandataria quien levantó la protección que había sobre la tierra sin convocar a los integrantes del Comité. ${ }^{47}$

En la venta realizada en 2009 a Poligrow ${ }^{48}$ Mejía Santamaría fue representada por su esposo, Gabriel Jairo Ángel Bernal, quien ha recibido títulos para explotar minas de metales preciosos en varios municipios de Antioquia. Por su parte, Poligrow asegura que es una empresa multinacional pero no tiene cultivos activos de palma africana en el país ni en otra parte del mundo. Esta firma creó un entramado de empresas de papel en España y Brasil ${ }^{49}$ que, por ejemplo, solo contrataron un empleado al año o fueron liquidadas, e inscribió como socio principal a una empresa en Uruguay, donde la información sobre empresas es restringida.

En la actualidad, las 5.500 hectáreas de Macondo son explotadas con un cultivo de palma aceitera, con una inversión de 25 millones de dólares,

45 Acta de desmovilización del Bloque Centauros, Resolución 107 de 2005, entrega de armas del grupo paramilitar en la finca Corinto, Yopal, Casanare, aprobada por el Alto Comisionado para la Paz, Presidencia de la República.

46 Ibíd. Protección registrada en folios de matrícula.

47 Testimonio del italiano Carlo Vigna Taglianti, representante de Poligrow. Entrevistas realizadas en enero y abril de 2013 por los periodistas María Teresa Ronderos, Óscar Parra e Ivonne Rodríguez en las instalaciones de Poligrow, en Bogotá.

48 Ibíd. Transferencias registradas en folios de matrícula.

49 Certificados mercantiles y de aportes en el registro español y brasileño, consultados en abril de 2013 . 
según aseguró el italiano Carlo Vigna Taglianti, ${ }^{50}$ el representante de la empresa. El caso de Poligrow fue denunciado ante el Congreso como acumulación ilegal de baldíos y el Instituto Colombiano para el Desarrollo Rural, Incoder, demandó ante la justicia ordinaria a esta empresa tras considerar que se había apropiado de tierras originalmente baldías. Sin embargo, el caso no fue aceptado por el juez.

\section{Periodización}

En los tres casos estudiados se pueden identificar cuatro momentos distintos, con la participación de diversos actores legales e ilegales:

\section{a. Década de 1950-1980}

En este período de treinta años ocurre la colonización de los Llanos Orientales con campesinos que vienen desplazados de otras regiones del país por la violencia bipartidista, pero también por extranjeros y ganaderos que ven en estas tierras una oportunidad para acumular grandes territorios. Este proceso sucede con explotaciones informales de la propiedad, donde colonos y hacendados llegan a acuerdos sobre el uso colectivo de la tierra.

\section{b. $1980-1990$}

En esta década hay una explosión de la violencia con las extorsiones y secuestros cometidos por la guerrilla pero también con la aparición de los primeros grupos de autodefensa financiados por narcotraficantes. Estos, bajo el pretexto de combatir a la subversión, buscaban un control del territorio para manejar el negocio de la droga y proteger sus tierras. Es también el período en que el antiguo Instituto Colombiano para la Reforma Agraria, Incora, comienza a formalizar la propiedad y a titular baldíos que se supone debían ser para campesinos. Los casos pusieron en evidencia que los beneficiarios no fueron precisamente sujetos de reforma agraria.

50 Testimonio del italiano Carlo Vigna Taglianti. 


\section{c. Finales de 1990-2006}

Es el período de consolidación de grupos paramilitares que, tras haber asesinado a líderes y haber cometido masacres y desplazamientos, hacen presencia permanente en el territorio e instalan bases de entrenamiento en algunas fincas. Es también el momento en que la región es controlada por el miedo y las acciones de este grupo ilegal, y en el que las tierras son abandonadas por los colonos originarios debido a la persistente violencia. Es además un período en el que las tierras que pertenecían a colonos sufren una transformación jurídica inicial, mediante titulaciones convenidas con el Incora por influencia de empresarios, compras fraudulentas y constitución de empresas que adquieren en el papel estos predios para luego venderlos.

\section{d. 2006 a la actualidad}

Es un período marcado, primero, por la desmovilización paramilitar y, como consecuencia, por tierras abandonadas por algún tiempo y que, en el papel, ya sufrían una transformación. A partir de 2007, los predios originalmente titulados por el instituto de tierras son englobados y transferidos a personas o empresas -algunas de ellas relacionadas con empresarios que actuaban en la vía legal e ilegal- quienes enseguida las vendieron a agroindustrias o las pusieron en explotación de empresas familiares. A partir de 2007, las tierras que se supone entre los años 50 y 90 fueron cultivadas con pancoger, entre finales de la década de los 90 y 2006 se convirtieron en campos de batalla y de entrenamiento paramilitar; en este último período los terrenos fueron sembrados con palma africana, cultivos de soya y maíz, o dedicados a la ganadería extensiva.

\section{Los actores}

En los casos estudiados coincide la participación de los siguientes actores legales e ilegales: 


\section{a. Campesinos colonos}

Son las personas sujetas a la reforma agraria que llegaron a los Llanos Orientales tras ser expulsadas por la violencia de la década de 1950. Después de varios años de explotar tierras baldías esperaban que el Estado les titulara una parcela como parte de la promesa del gobierno de realizar una reforma agraria. En Puerto Gaitán, algunos de estos campesinos, como los de la vereda La Cristalina, predio El Brasil, alcanzaron a ser titulados, pero otros no, como los colonos del caserío El Porvenir, predio Hato Cabiona. En Mapiripán los colonos no lograron títulos porque estos fueron otorgados a extranjeros o ganaderos que tenían influencia y poder.

\section{b. Ganaderos y hacendados}

Con ayuda del antiguo Instituto Colombiano para la Reforma Agraria, Incora, hoy Incoder, un ganadero, como en el caso de Mapiripán, y Víctor Carranza, terrateniente y empresario de las esmeraldas en los casos de Puerto Gaitán, lograron que el instituto de tierras les titulara terrenos baldíos que debían ser para campesinos. El primero, aunque no era sujeto de reforma agraria, terminó siendo víctima porque tuvo que abandonar el predio por la violencia y la tierra le fue usurpada por dos personas que luego se la vendieron a la empresa Poligrow. El segundo, actuando desde la legalidad (empresario) pero también desde la ilegalidad (por financiar un grupo paramilitar) no solo logró la titulación de predios baldíos sino transferirlos luego a empresas agroindustriales, como en el caso de El Brasil-La Fazenda.

\section{c. Grupos paramilitares}

En Puerto Gaitán, la expulsión de los colonos y la apropiación de tierras baldías fue provocada por el grupo paramilitar 'Los Carranceros', financiado por el esmeraldero Víctor Carranza. En Mapiripán la expulsión de la población ocurrió tras la masacre y los desplazamientos propiciados por el Bloque Centauros de las AUC, grupo paramilitar venido desde Córdoba, financiado por los hermanos narcotraficantes Carlos y Vicente Castaño. Ambos grupos paramilitares instalaron sus bases de operación y de 'entrenamiento' en táctica militar y manejo de armas en estos territorios. 


\section{d. Instituto Colombiano para la Reforma Agraria, Incora}

Funcionarios del Instituto de Tierras, creado en 1961 para distribuir la propiedad rural entre campesinos pobres, se aliaron con ganaderos y empresarios para titularles tierras a estos últimos, que no eran sujetos de reforma agraria. El Instituto respondió, como se muestra en los casos, a intereses de grupos de poder, expidiendo resoluciones de adjudicación e incumpliendo los requisitos para la titulación.

\section{e. Funcionarios del registro y alcalde}

Otros funcionarios públicos también respondieron a los intereses particulares de empresarios, como el caso de Víctor Carranza. La entonces notaria 4a de Villavicencio, Gloria Emma Camacho, y el registrador de Puerto Gaitán, Jairo Alfonso Gutiérrez, facilitaron la inscripción de los predios, primero en escrituras y luego en folio de matrícula, legalizando así la acumulación de tierras de origen baldío.

En el caso de Mapiripán, la entonces alcaldesa, Maribel Mahecha, levantó la medida de protección que había sobre los predios para que la empresa Poligrow pudiera comprar las tierras. Mahecha violó los procedimientos que se requerían en este caso para eliminar la restricción, pues ni si quiera citó a los integrantes del Comité de Atención a la Población Desplazada.

\section{f. Fuerza pública}

La presencia del Estado fue tácita en los tres casos, porque permitieron la entrada y la permanencia de grupos paramilitares que cometieron masacres, desplazamientos y despojos de tierras en esta zona de los Llanos Orientales.

\section{Los mecanismos}

Los tres casos estudiados ponen en evidencia mecanismos que operaron sobre la transformación de la propiedad rural en Colombia: 


\section{a. La coerción}

La coerción aparece en distintos momentos y es antecedida o sucedida por la colonización de las tierras baldías, los intentos de reforma agraria, los procesos de acumulación o el despojo. En el caso uno, La Fazenda, en Puerto Gaitán, la coerción es ejercida por un grupo paramilitar que instala su base o centro de operaciones en un terreno que había sido titulado por el antiguo Instituto Colombiano para la Reforma Agraria - Incora, hoy Incoder - (autoridad de tierras) a campesinos. En este caso, los paramilitares utilizaron la violencia para apropiarse de un lugar que consideraban estratégico para cometer sus delitos. Esta coerción, ejercida por años, es utilizada posteriormente por la familia de un esmeraldero para transferir la propiedad a una agroindustria.

En el caso dos, La Cristalina, también en Puerto Gaitán, la coerción se manifiesta en tres momentos: el primero, cuando los paramilitares asesinaron a líderes campesinos después del proceso de colonización; el segundo, al consolidarse la presencia paramilitar en la región; y el tercero, cuando una empresa ganadera amenazó a los campesinos originarios con que tenían que salir de las tierras porque, supuestamente, estas eran de su propiedad. En el caso tres, en Mapiripán, Meta, la coerción es ejercida primero por guerrilleros y luego por paramilitares para controlar el territorio, financiarse con el cobro de extorsiones y manejar el negocio del narcotráfico.

La coerción fue ejercida por legales e ilegales. A través de ella, guerrilleros y paramilitares controlaron el territorio en función de sus intereses, y empresarios - como la ganadería La Cristalina- atemorizaron a los antiguos colonos para que abandonaran las tierras. Pero, como se explicó anteriormente, además de la coerción, las alianzas entre grandes propietarios y los grupos paramilitares fue otro medio para lograr la titulación y la transferencia de la tierra.

En los casos uno y dos, el esmeraldero Víctor Carranza, señalado de haber financiado al grupo paramilitar conocido como 'Los Carranceros', utilizó a este actor armado para que los campesinos que originalmente fueron titulados, entregaran la tierra a la familia Carranza y esta, a su vez, pudiera negociarla con la empresa La Fazenda. De igual manera, a través de este grupo paramilitar fueron asesinados los primeros colonos del antiguo 
Hato Cabiona mientras la familia del esmeraldero lograba la titulación de la tierra, que luego fue explotada por una empresa ganadera de su esposa.

Además de esta alianza de legalidad (empresario) e ilegalidad (grupo armado), mediante mecanismos legales, la tierra que se suponía era para los pequeños propietarios, terminó en manos de los grandes terratenientes. La reforma agraria fue una política de gobierno desde la década de los años 30 pero no fue ejecutada para cumplir con su principal objetivo, entregarles tierras a los campesinos.

En los casos dos y tres, la reforma agraria, mecanismo legal, fue cooptada por grupos de poder en su favor. Con la influencia de la familia Carranza, 27 personas no originarias de Puerto Gaitán, que no habían pisado las tierras del antiguo Hato Cabiona y, por tanto, ajenas a los colonos originarios, fueron tituladas como beneficiarias de la reforma por el antiguo Incora. Luego estas personas les transfirieron la tierra a otros amigos de la familia para que fuera explotada por la empresa ganadera propiedad de los Carranza.

En Mapiripán, el dueño originario de los terrenos conocidos como Macondo, que en la actualidad son explotados por la empresa Poligrow, logró que el antiguo Incora le titulara a él y a su administrador 5.000 hectáreas de tierras baldías, sin cumplir los requisitos de la reforma. Él era un próspero ganadero antioqueño que tenía la capacidad para adquirir tierra, pero, al igual que otros ganaderos de su región, utilizó el nombre de su mayordomo para lograr la adjudicación.

\section{b. Violación a las leyes}

Otra vía de titulación y transferencia de la propiedad rural fue la violación a las leyes rurales. Además de incumplir los requisitos que se supone garantizaban beneficiarios reales de la reforma agraria (campesinos sin tierra), en los tres casos los actores de poder (esmeraldero y ganadero) violaron la Ley 160 de 1994 y la Resolución 041 de 1996, que establecen los límites de titulación cuando las tierras son de origen baldío. En todos los casos, la tierra fue acumulada y transferida a las tres empresas: la industria de cárnicos, la palmera y la ganadería.

Estas empresas, a su vez, también incumplieron dichas normas por explotar tierras acumuladas. En el momento en que estas compraron la propiedad a la familia Carranza (caso La Fazenda) o a unos antioqueños 
(caso Poligrow), las compañías violaron la Ley, por ejemplo, para el caso de La Fazenda, creando diez empresas para hacer las compras, y en el caso de Poligrow, acudiendo a una supuesta nueva interpretación de la Ley 160 para poder acumular. Poligrow, además, en confabulación con la ex alcaldesa de Mapiripán, violó la protección que había sobre las tierras de esta región, las cuales tras la masacre paramilitar de 1997, habían sido protegidas. Sin embargo, la empresa logró que dicha funcionaria suprimiera la protección sin convocar el respectivo Comité de Atención para la Población Desplazada, encargado de tomar tal decisión.

Estas violaciones a la Ley evidencian en los tres casos que el Estado de derecho, regido por un sistema de leyes e instituciones que suponen un orden público, no protege a los pequeños propietarios.

Pese a existir un proyecto histórico de reforma agraria, es decir, de redistribución de la tierra, apoyado por leyes y normas que proscriben la acumulación -como las mencionadas-, los colonos y campesinos originarios que cumplían con los requisitos para recibir una parcela no la tuvieron ni jurídica ni materialmente. A quienes fueron titulados por ley, como ocurrió en Puerto Gaitán para el caso de La Fazenda, la tierra les fue arrebatada bajo presión, y transferida a una empresa de la familia Carranza. Quienes llevaban veinte años esperando la titulación, caso de La Cristalina, nunca fueron titulados porque las tierras se adjudicaron a una red de amigos y supuestos testaferros del esmeraldero Víctor Carranza. En el caso Poligrow, los titulados fueron los ganaderos y no los colonos que llegaron a estas tierras en los años cincuenta.

\section{c. Coalición entre grupos armados, empresarios y funcionarios}

Los tres casos evidencian que algunos grandes empresarios tejieron coaliciones con grupos armados ilegales y salieron victoriosos en la acumulación de la propiedad rural. La familia Carranza utilizó su poder e influencia para lograr que el antiguo Incora les titulara tierras, y la vía armada, con la financiación del grupo paramilitar conocido como 'Los Carranceros', para 'despejar' los territorios que les interesaban. Pero en estas coaliciones también participaron instituciones y funcionarios, como ocurrió con la Notaría $4^{\text {a }}$ de Villavicencio y la Oficina de Instrumentos Públicos de Puerto Gaitán 
-que permitieron los englobes de los predios El Brasil y Hato Cabiona-, y la Alcaldesa de Mapiripán, que levantó la medida de protección a las tierras de Macondo para que Poligrow las pudiera comprar. Así mismo, funcionarios del antiguo Incora, como se explicó anteriormente, respondieron en su momento a intereses del empresario Víctor Carranza o de ganaderos a la hora de hacer las titulaciones de baldíos.

\section{d. Competencia y acumulación}

El liberalismo económico, que impuso un sistema regulado por el mercado, cuyo objetivo es asegurar un orden en la producción y distribución de bienes, y en el que se supone existen derechos claros de propiedad, no eliminó la coerción. Por el contrario, tal modelo generó una competencia por acumular cada vez más tierra - a través de vías legales e ilegales y de la fuerza- que se tradujo en más violencia. Los tres casos analizados, en los que hubo titulación y transferencia de la propiedad, incorporan historias de desplazamientos, masacres y amenazas ocurridos en la década de los 90.

En el campo, la desmovilización de los grupos paramilitares (20052006) se tradujo en una transformación jurídica y material de la propiedad. En el periodo en que estos actores armados hicieron presencia en el territorio, explotando las tierras que arrebataron a campesinos y colonos originarios, las tierras fueron controladas por la vía armada ilegal. Posteriormente, a partir de 2007, los predios fueron tapizados con palma, soya, maíz y ganado. En esta transformación de la propiedad, por lo menos en los casos de La Fazenda y La Cristalina, se puede hablar de "blanqueamiento". La familia Carranza se hizo a tierras de forma ilegal para luego negociarlas. En el primer caso lo logró con una agroindustria, y en el segundo no, pese a intentarlo con una empresa familiar. Lo anterior sugiere entonces que la competencia por acumular tierras se mantuvo y que, por ello, hay una continuidad en el acaparamiento de tierras.

Es decir, el espíritu de hacer una redistribución de la propiedad no se logró porque las grandes extensiones de tierras, controladas por actores legales e ilegales, siguen jurídica y materialmente explotadas en igualdad de proporciones, ahora, por agroindustrias. 


\section{Conclusiones}

- Los mecanismos desarrollados por el gobierno para desarrollar una reforma agraria, una redistribución de la tierra, no garantizan seguridad en los derechos de propiedad. Estos producen una persistente inestabilidad y, por tanto, atentan contra el Estado de Derecho. Esto se explica en que los derechos de propiedad no fueron asignados conforme a los requisitos de la Ley sino por medio de coaliciones entre actores legales e ilegales, con incidencia desde la región hacia el poder central y a través de la persistente coerción ejercida por los grupos armados.

- Esta inestabilidad en los derechos de propiedad desató constantes ciclos de despojo perpetrados por actores legales e ilegales, en una competencia constante por acumular más tierra o explotar extensos territorios por un interés particular: en el caso de los actores armados, por control territorial y protección a hacendados y negocios ilegales, y de los legales, por protección a sus tierras y garantía de crecimiento de su riqueza con la transferencia de tierras.

- La ocupación paramilitar de la década de 1990 marca un periodo de desplazamiento de los colonos y un estancamiento en la productividad de las tierras rurales. La desmovilización de 2006 produce un abandono temporal de estos predios y un año después, 2007, comienza una transformación de la propiedad. Este año es clave dado que los tres casos muestran que hay un cambio jurídico y material de las tierras de origen baldío. Son acumuladas, comercializadas y luego transferidas a agroindustrias o ganaderías para su explotación. Esta transformación es legalizada a través del registro público en notarías y oficinas de instrumentos públicos.

- Dado que el despojo fue legalizado con mecanismos ofrecidos por el Estado, como la titulación de predios vía Instituto de Tierras e inscripción en el registro público, resulta imposible que el proceso de restitución que se adelanta en Colombia limite la documentación de los casos a la responsabilidad de los actores ilegales. El despojo fue producto de una coalición entre legales e ilegales, por lo que se sugiere que las demandas de tierras que presenta la Unidad de Restitución ante los jueces especializados incorporen todos los actores que participaron en los desplazamientos, las titulaciones y las cadenas de transferencia 
de la propiedad rural. En este sentido, el concepto de comprador de buena fe es debatible puesto que las tierras rurales fueron tituladas y comercializadas a través de estas coaliciones, coerción y cooptación de la institucionalidad.

- Este estudio de caso invita a una nueva agenda de investigación que permita comprender los mecanismos de despojo y los actores que han influido en la transferencia y concentración de tierras baldías en la región de la altillanura en otros municipios del Meta como Puerto López y del vecino departamento del Vichada en Puerto Carreño, La Primavera y Santa Rosalía. En por lo menos cinco debates de control político realizados en el Congreso han sido expuestos casos de agroindustrias nacionales y extranjeras que han concentrado tierras de origen baldío. Sin embargo, no ha habido una investigación profunda que haya identificado el pasado de estas tierras en relación con los ciclos de violencia y los fallidos intentos de reforma agraria.

\section{Referencias}

\section{Bibliográficas}

Alcaldía de Mapiripán (2007). La otra Mapiripán, relatos que reconstruyen la historia del pueblo. Mapiripán, Meta, Colombia: Alcaldía de Mapiripán.

Centro de Investigación y Educación Popular, Cinep (2004). Deuda con la humanidad: paramilitarismo de Estado en Colombia, 1988-2003. Bogotá: Cinep, Informe Noche y Niebla.

Departamento Nacional de Planeación (2010). Plan Nacional de Desarrollo 2014, "Prosperidad para todos". Bogotá: Presidencia de la República de Colombia.

Fitzpatrick, D. (2006). Evolution and Chaos in Property Rights Systems. The Third World Tragedy of Contested Access. The Yale Law Journal, 1002, 996-1048.

Grupo de Memoria Histórica de la Comisión Nacional de Reparación y Reconciliación (2010). La tierra en disputa. Memorias del despojo y resistencias campesinas en la costa Caribe 1960-2010. Bogotá: Editorial Taurus y Ediciones Semana.

Reyes Posada, A. y otros (2009). Guerreros y campesinos. El despojo de la tierra en Colombia. Bogotá: Editorial Norma. 
Salinas Abdala, Y. (2011). Dinámicas en el mercado de la tierra en Colombia. Bogotá: Documento elaborado para la Oficina Regional de la FAO para América Latina y el Caribe, 2011.

\section{Periodísticas}

'Don Mario': sin Justicia y Paz y a la espera de extradición, historia del ex jefe paramilitar y su participación en el Bloque Centauros, a partir de las versiones libres y juicios como parte del proceso de Justicia y Paz (s.f.).VerdadAbierta.com. Recuperado de http://www.verdadabierta.com/justicia-y-paz/juicios/4881-excluyena-don-mario-de-justicia-y-paz

'Los Carranceros' que se tomaron el Oriente del Meta. (2012, 9 de marzo). VerdadAbierta.com. Recuperado de http://www.verdadabierta.com/justicia-y-paz/ imputaciones/3896-los-carranceros-que-se-tomaron-puerto-gaitan-y-puerto-lopez

Los últimos minutos de 'Don Pedro Esmeralda' en el centro de Bogotá. (2013, 26 de julio). El Tiempo. Recuperado de http://www.eltiempo.com/justicia/ARTICULOWEB-NEW_NOTA_INTERIOR-12950484.html

Tres agroindustrias compraron tierras con líos y violencia (s.f.). VerdadAbierta.com. Recuperado de http://www.verdadabierta.com/tres-agroindustrias-de-los-llanoscompraron-tierras-con-lios-y-violencia

\section{Leyes y decretos}

Colombia. Congreso de la República (1994). Ley 160. Bogotá: Diario Oficial 41.479. Colombia. Congreso de la República (2011). Ley 1448. Bogotá: Diario Oficial 48.096. Colombia. Instituto Colombino de Reforma Agraria (1996). Resolución 041. 